\title{
LANDASAN AGAMA DALAM PENDIDIKAN PUBERTAS DI SEKOLAH DASAR
}

\author{
Erry Utomo ${ }^{1}$, Nurfadhilah ${ }^{2}$, Agung Purwanto ${ }^{1}$, Jatu Wahyu Wicaksono ${ }^{1}$, Alrahmat Arif ${ }^{1}$ \\ ${ }^{1}$ Universitas Negeri Jakarta, Indonesia \\ ${ }^{2}$ Universitas Muhammadiyah Jakarta, Indonesia \\ E-mail: erry30.utomo@gmail.com
}

\begin{abstract}
Indonesia is experiencing a demographic bonus, and a good education and health situation will determine the quality of human resources so that this situation does not turn into a demographic burden or disaster. The Indonesian Adolescent Reproductive Health Survey shows the in-depth knowledge of adolescents about puberty, whereas adolescence is a golden period that will determine the quality of the next generation. This study aims to get a picture of the perception of teachers and students in particular about puberty and its relation to religion. The approach used is qualitative, data collected by conducting in-depth interviews with teachers, parents, and students. There were ten informants, consisting of teachers, parents, and students from 2 public and religious-based elementary schools in North Jakarta. In general, teachers have low knowledge / understanding of puberty, as well as students' knowledge. Most teachers have the perception that education about puberty in the classroom, according to the curriculum, turns out to be too vulgar so that some information is not conveyed to students. Religion is considered as the most reliable foundation in shaping student behavior. Teachers tend to hand over responsibility to religious teachers to deliver material on puberty, at religiously-based schools specifically mentioned teachers of fiqh. Teacher capacity building is needed regarding the material that must be taught, and it is delivery methods to suit the needs of students and have an impact on improving knowledge and improving behavior.
\end{abstract}

Keywords: elementary school; religious-based school; puberty education

Abstrak. Indonesia sedang mengalami bonus demografi dan situasi pendidikan dan kesehatan yang baik sangat menentukan kualitas sumber daya insani agar situasi ini tidak berbalik menjadi beban atau bencana demografi. Survei Kesehatan Reproduksi Remaja Indonesia memperlihatkan rendahnya pengetahuan remaja tentang pubertas, padahal masa remaja merupakan periode emas yang akan menentukan kualitas generasi berikutnya. Penelitian ini bertujuan mendapatkan gambaran persepsi guru dan peserta didik di khususnya tentang pubertas dan kaitannya dengan agama. Pendekatan yang digunakan yaitu kualitatif, data dikumpulkan dengan melakukan wawancara mendalam kepada guru, orang tua, dan peserta didik. Jumlah informan 10 orang, terdiri dari guru, orang tua, dan peserta didik dari 2 sekolah dasar umum dan berbasis agama di Jakarta Utara. Secara umum guru memiliki pengetahuan/pemahaman yang rendah tentang pubertas, demikian pula pengetahuan peserta didik. Kebanyakan guru memiliki persepsi bahwa edukasi tentang pubertas di kelas sesuai kurikulum ternyata dianggap terlalu vulgar sehingga sebagian informasi tidak disampaikan kepada peserta didik. Agama dianggap sebagai landasan paling diandalkan dalam membentuk perilaku peserta didik. Guru cenderung menyerahkan tanggung jawab kepada guru agama untuk menyampaikan materi tentang pubertas, pada sekolah berbasis agama disebutkan secara spesifik guru fiqih. Dibutuhkan pengembangan kapasitas guru tentang materi yang harus diajarkan dan metode penyampaiannya agar sesuai dengan kebutuhan peserta didik dan berdampak terhadap peningkatan pengetahuan serta perbaikan perilaku.

Kata Kunci: sekolah dasar; sekolah berbasis agama; pendidikan pubertas

Permalink/DOI: https://doi.org/10.15408/harkat.v15i1.13440 


\section{Pendahuluan}

Pendidikan tentang pubertas belum menjadi hal yang umum dilakukan di sekolahsekolah Indonesia, apalagi pada jenjang sekolah dasar baik sekolah umum maupun berbasis agama. Padahal, hal ini merupakan prasyarat untuk pembentukan perilaku sehat dan bertanggung jawab sejak menjelang remaja. Kesehatan reproduksi dan seksual, baik layanan maupun informasi dalam pendidikan seks komprehensif merupakan prasyarat untuk keberhasilan Tujuan Pembangunan Berkelanjutan (Biccard, 2018). Intervensi harus dilakukan sejak dini, karena efektifitas program menurun seiring pertambahan usia (Smith, Panisch, Malespin, \& Graça Pereira, 2017).

Kematangan prematur terutama pada remaja perempuan, mengakibatkan beberapa situasi, misalnya gangguan/hambatan pertumbuhan fisik tertentu (O’Keeffe, Frysz, Bell, Howe, \& Fraser, 2019; Week, 2018), fisik sekaligus mental dan sosial (Campisi et al., 2019), bahkan juga berhubungan dengan usia orang tua (Horak, Valge, Fischer, Magi, \& Kaart, 2018). Remaja Indonesia memiliki pengetahuan yang relatif rendah tentang tanda fisik spesifik pubertas, padahal responden berusia lebih dari 14 tahun, usia yang umumnya sudah mengalami proses pubertas. Orang tua dan guru bukan merupakan orang yang dipilih untuk mendiskusikan kejadian terkait kesehatan reproduksi remaja. Mereka juga hampir 90\% memiliki akses internet (BPS, BKKBN, Kemenkes, \& USAID, 2017) sebagai sumber informasi dan hiburan. Penelitian lain juga menemukan terbatasnya peran orang tua dalam mendidik anak yang mengalami pubertas. Anak sering menunjukkan perilaku buruk terhadap orang tua dan lingkungan (Sari, 2017). Situasi keuntungan demografi yang sedang dinikmati Indonesia harus diintervensi agar tidak berbalik menjadi beban atau bencana.

Guru mengalami tantangan tersendiri saat menyampaikan informasi kesehatan reproduksi dan seksual sehingga dirasa perlu melibatkan profesional kesehatan atau psikolog di sekolah (Tabong et al., 2018). Sejatinya kita tidak perlu merancang dan membangun 'kebutuhan' (demand) maupun program, tetapi cukup dengan menjelaskan sifat dasar anak (childnature) (Steiner, 1996). Penelitian ditujukan untuk mendapatkan gambaran mispersepsi guru, orang tua, dan peserta didik di kelas tinggi sekolah dasar khusus tentang materi terkait pubertas.

\section{Metode}

Penelitian menggunakan pendekatan kualitatif, dengan desain studi fenomenologi. Data diambil melalui wawancara mendalam yang melibatkan 10 informan terdiri dari 6 guru, 1 orang tua, dan 3 peserta didik yang mengajar atau (anaknya) belajar di jenjang sekolah dasar. Sekolah dasar yang dipilih yaitu sekolah umum (SD negeri) dan sekolah swasta berbasis agama di Jakarta Utara. Pengumpulan data dilakukan pada Agustus 2019.

\section{Hasil dan Pembahasan}

\section{Karakteristik informan}

Informan berjumlah 9 orang dengan karakteristik sebagaimana diuraikan pada tabel 1.

Table 1. Karakteristik informan.

\begin{tabular}{|c|c|c|c|c|c|}
\hline Kode & Status & Usia & Sex & kelas & jenis sekolah \\
\hline P1 & $\begin{array}{l}\text { peserta } \\
\text { didik }\end{array}$ & 10 & Perempuan & IV & umum, negeri \\
\hline P2 & $\begin{array}{l}\text { peserta } \\
\text { didik }\end{array}$ & 11 & Perempuan & $\mathrm{V}$ & agama, swasta \\
\hline P3 & $\begin{array}{l}\text { peserta } \\
\text { didik }\end{array}$ & 10 & Perempuan & III & umum, negeri \\
\hline $\mathrm{O} 1$ & $\begin{array}{l}\text { orang } \\
\text { tua }\end{array}$ & 33 & Perempuan & IV & umum, negeri \\
\hline G1 & guru & 53 & laki-laki & VI & umum, negeri \\
\hline G2 & guru & 32 & perempuan & $\bar{V}$ & agama, swasta \\
\hline Kode & Status & Usia & Sex & \multicolumn{2}{|c|}{ kelas jenis sekolah } \\
\hline G3 & guru & \multicolumn{2}{|c|}{ perempuan IV } & \multicolumn{2}{|c|}{ umum, negeri } \\
\hline$\overline{G 4}$ & guru & \multirow{2}{*}{\multicolumn{2}{|c|}{$\begin{array}{ll}\text { perempuan } & \mathrm{V} \\
\text { perempuan } & \mathrm{V}\end{array}$}} & \multicolumn{2}{|c|}{ agama, swasta } \\
\hline G5 & guru & & & \multirow{2}{*}{\multicolumn{2}{|c|}{$\frac{\text { agama, swasta }}{\text { agama, swasta }}$}} \\
\hline G6 & guru 41 & \multicolumn{2}{|c|}{ perempuan $\mathrm{V}$} & & \\
\hline
\end{tabular}




\section{Pengetahuan Tentang Pubertas}

Pemahaman guru tentang pubertas bervariasi. Sebagian memiliki pengetahuan yang cukup, terlihat dari kemampuan menjelaskan tanda perubahan spesifik pubertas, namun umumnya pengetahuannya sangat terbatas. Tanda fisik primer (menstruasi dan mimpi basah) dapat dijelaskan oleh hampir semua guru, hal ini sesuai dengan data SKRRI bahwa mulai haid merupakan tanda pubertas paling populer (89\%) (BPS et al., 2017). Namun tanda lain seperti percepatan pertumbuhan badan (tinggiberat-bentuk), perubahan bentuk dada, jakun, rambut di bagian tubuh tertentu dll. hanya disebutkan oleh sebagian kecil guru. Perubahan emosi juga disebutkan oleh beberapa guru, sehingga dirasa perlu diwaspadai terjadinya konflik dan permusuhan (tawuran) di antara remaja.

Pemahaman tersebut kemudian dilahirkan dalam proses pembelajaran. Beberapa guru menyebutkan penyampaian materi terkait pubertas dilakukan di kelas tinggi (5 dan 6), namun mereka fokus pada kelas yang diampu, tidak saling mengetahui apa lagi berkoordinasi tentang materi sejenis yang disampaikan di kelas lain atau oleh guru lain. Guru yang mengajar di sekolah berbasis agama lebih banyak menyebutkan materi spesifik pubertas dibanding mereka yang mengajar di sekolah umum. Beberapa perubahan fisik disebutkan oleh guru di kedua jenis sekolah (pertumbuhan otot, perubahan suara, menars dan mimpi basah), namun aspek psikososial lebih banyak disebutkan oleh guru yang mengajar di sekolah agama (kemunculan hasrat seksual, akibat jika melakukan aktivitas seksual, dan adab bergaul dengan lawan jenis). Sebagian guru yang mengajar di sekolah umum mengatakan tidak ada hubungan antara aspek agama/religius dan pubertas, sedangkan aspek fisik, emosi, dan sosial disebutkan memiliki hubungan dengan pubertas oleh semua guru, baik yang mengajar di sekolah umum maupun berbasis agama.
Perubahan perilaku yang disebutkan oleh beberapa guru terutama lebih memperhatikan penampilan, mulai bercermin dan berdandan (terutama pada perempuan), suka kepada lawan jenis, dan mulai menggunakan istilah 'pacar' serta berupaya mencari perhatian. Aspek religius yang ditekankan para guru yaitu kewajiban melakukan ibadah ketika sudah aqil baligh serta menutup/melindungi bagian 'atas' yaitu sekitar dada dan 'bawah' yaitu sekitar alat genital terutama bagi perempuan. Baik guru pada sekolah umum negeri maupun swasta agama tergambar memiliki pemahaman serupa tentang hal ini.

Baik guru wali kelas laki-laki maupun perempuan merasa tidak nyaman saat membawakan materi terkait pubertas, pendidikan reproduksi, dan seksualitas. Guru yang mengajar di sekolah umum negeri menemukan materi pembelajaran terkait pubertas atau reproduksi pada kelas 6, dan di sekolah agama pada kelas 5. Mereka melakukan seleksi materi yang akan disampaikan di kelas sehingga tidak semua materi dibahas karena dianggap terlalu vulgar. Penelitian menemukan bahwa sekitar $80 \%$ kebutuhan pendidikan pubertas meliputi tema 'pendidikan kesehatan kulit', 'pendidikan gizi', 'pendidikan tentang perubahan emosi', metode pengajaran penularan dan pencegahan HIV dan penyakit menular seksual lainnya, dan 'pelatihan tatalaksana menstruasi normal maupun nyeri serta penyebabnya' (Alidadi, Sabzevari, Pouraboli, \& Forozy, 2019).

Peserta didik tinggal bersama orang tua kandung dan seorang adik. Mereka tinggal di rusunawa yang terdiri dari 2 kamar, anak tertua memiliki kamar sendiri. Pemahaman peserta didik relatif terbatas tentang tanda pubertas. Salah satu informan sudah mengalami menstruasi saat duduk di kelas 4. Kedua informan diajari sejak dini (saat balita atau TK) tentang melindungi bagian tubuh atas dan bawah serta larangan dilihat atau disentuh oleh 
siapapun kecuali ibunya, tetapi larangan ini datang dari ibunya sendiri yang juga mengajar di sekolah tempat informan belajar.

Pengetahuan peserta didik tentang tanda pubertas relatif terbatas. Salah satu peserta didik hanya menjawab 'dewasa' saat ditanya tentang pubertas tanpa menjelaskan tanda spesifik. Peserta didik menyatakan perasaan mereka 'biasa saja' saat topik tentang reproduksi dan pubertas dibahas di kelas. Gambaran sebaliknya dinyatakan oleh para guru yang mengalami hambatan saat memulai kelas karena para anak didik akan saling bertanya dan mengejek kawannya, terutama tentang menstruasi. Para gadis dipersepsi oleh guru merasa malu karena sebagian temannya melakukan bully. Tanda lain yang juga tidak kalah penting yaitu percepatan pertumbuhan (berat-tinggi-bentuk tubuh) hanya disebutkan oleh beberapa guru. Padahal, tanda ini penting dikenali agar dapat diintervensi untuk mengantisipasi situasi pertumbuhan fisik pada masa datang yang juga bisa berdampak pada aspek sosio-psikologis remaja. Banyak remaja juga terancam mengalami gangguan pertumbuhan karena pola makan yang salah.

Peserta didik yang duduk di kelas rendah memiliki pengetahuan yang sangat rendah tentang pubertas. Konsep 'besar'-'kecil' untuk menggambarkan pertumbuhan fisik juga dinyatakan tidak dibahas di sekolah, namun di rumah para peserta didik membicarakannya dengan ibu. Pesan yang ditangkap peserta didik agar tidak lagi berlaku 'kolokan' (manja). Pesan penting bahwa periode emas ini harus didukung dengan pengetahuan dan perilaku gizi (makan), aktivitas fisik (olah raga), dan persiapan mental dan sosial (pembelajaran tentang etika dan keterampilan komunikasi) tidak disebutkan.

\section{Metode pembelajaran}

Para guru menggunakan cara pembelajaran terbatas untuk menyampaikan materi pubertas untuk menghindari kegaduhan dalam kelas. Sejak awal disampaikan, peserta didik sudah merespon dengan tertawa dan bercanda sehingga guru cenderung merasa tidak nyaman melanjutkan. Teknik yang umum digunakan yaitu bercerita dan bertanya untuk dilanjukan dengan diskusi. Guru tidak menggunakan gambar dan video untuk menjelaskan karena dianggap terlalu vulgar. Penelitian justru memperlihatkan efektifitas video sebagai media edukasi pubertas, dengan syarat pendampingan guru atau orang tua (Hurwitz et al., 2018).

Umumnya mereka menganggap bahwa materi lebih cocok disampaikan oleh guru agama pada sekolah umum dan guru yang mengajar Fikih pada sekolah berbasis agama. Para informan menganggap bahwa pendidikan agama dapat menjadi pintu masuk edukasi sekaligus memberikan dasar pemahaman untuk kemudian berperilaku terpuji (akhlak karimah). Intervensi berupa penyuluhan memiliki hubungan dengan pengetahuan dan sikap remaja putri dalam menghadapi pubertas (Aryastuti, 2012).

Sebaliknya dengan para pengajar, peserta didik mengaku merasa biasa saja saat membahas materi tersebut. Guru sebaiknya melakukan kreasi dan inovasi saat menyampaikan materi pubertas yang terintegrasi dalam pendidikan dasar (Nurfadhilah, 2019). Implementasi berbagai metode bisa dilakukan seperti belajar menemukan/inkuiri (discovery learning/inquiry learning), belajar berbasis masalah (problem based learning), belajar berbasis projek (project based learning), dan belajar kooperatif (cooperative learning). Guru juga perlu mengakomodasi beragam kecerdasan dan gaya belajar sesuai minat peserta didik. Peserta didik juga perlu diberi kepercayaan untuk memegang tanggung jawab tertentu dalam program sekolah (Suhardi et al., 2018).

Kedua sekolah menerapkan koedukasi, kelas peserta didik laki-laki dan perempuan digabung, termasuk saat memberi materi terkait pubertas. Kegaduhan saat proses pembelajaran terjadi karena sebagian peserta didik saling bertanya dan mengejek temannya yang belum 
atau sudah mengalami tanda primer, terutama yang menjadi 'korban' peserta didik perempuan. Sebagian orang meyakini bahwa koedukasi akan mengarahkan pada pubertas prematur dan pada gilirannya mengarah pada penerimaan/kesukaan erotis atau malah kehilangan rasa saling tertarik. Kelompok yang mendukung koedukasi menyatakan bahwa pengalaman bermain dan belajar di sekolah merefleksikan kehidupan nyata dalam keluarga dan masyarakat yang akan mengarah pada normalisasi keterhubungan lakilaki dan perempuan, meningkatkan pertemanan dan persaudaraan, bukan erotisme berlebihan (Dormus, 2019).

Intervensi dapat juga dilakukan secara terpisah kepada masing-masing gender. Penelitian menunjukkan pengaruh edukasi dengan pengetahuan dan sikap remaja (Aryastuti, 2012). Pendidikan merupakan interaksi kompleks/rumit antara tubuh (body), jiwa (soul), dan ruh (spirit)

(Steiner, 1996). Agama dalam hal ini menjadi aspek yang tak terpisahkan dan mendasari proses pendidikan.

Selain sekolah, pendidikan juga harus dilaksanakan di rumah oleh keluarga/orang tua, namun masih banyak orang tua yang memiliki keterbatasan untuk mendidik anak tentang pubertas. Cara orang tua menanggapi perilaku kurang terpuji anak umumnya memarahi atau menasehati langsung (Sari, 2017).

\section{Penutup}

Miskonsepsi guru, orang tua, dan peserta didik dalam pembelajaran pubertas dirasakan dan berdampak pada pengetahuan serta pemahaman kedua belah pihak yang rancu. Beberapa informasi disampaikan secara terbatas oleh guru dan mengakibatkan tidak terbukanya informasi yang didapat peserta didik. Guru dan orang tua juga cenderung menyerahkan tanggung jawab pendidikan pubertas kepada guru agama dan guru fiqih secara khusus, padahal semua guru memiliki peran sesuai bidang yang diampu. Diperlukan intervensi untuk menjembatani kesenjangan misalnya berupa peningkatan kapasitas guru, baik dalam hal penguasaan konsep dan materi inti pubertas maupun metode penyampaiannya.

\section{Daftar Pustaka}

Alidadi, Z., Sabzevari, S., Pouraboli, B., \& Forozy, M. A. 2019. The Attitude and Educational Needs of The First-Year Students about Sex Education in South ast Iran. I-Managers Journal on Nursing, 9(1), 1-11.

Aryastuti, N. 2012. Pengaruh Penyuluhan tentang Pubertas terhadap Pengetahuan dan Sikap Remaja Putri Menghadapi Pubertas di MTS Ibnul Qoyyim Putri Berbah Sleman.

Biccard, B. M. 2018. Addressing the unfinished agenda on sexual and reproductive health and rights in the SDG era, 6736(18), 2581-2584.

https://doi.org/10.1016/S0140-

6736(18)30890-0

BPS, BKKBN, Kemenkes, \& USAID. 2017. Survei Demografi dan Kesehatan Indonesia 2017 Kesehatan Reproduksi Remaja. Survei Demografi Dan Kesehatan Indonesia, 28(12), 1407- 1408. https://doi.org/10.1016/B978-0-12804024-9/00048-3

Campisi, S. C., Wasan, Y., Soofi, S., Monga, S., Korczak, D. J., Lou, W., ... Bhutta, Z. A. 2019. Nash-wo-Numa ( childhood growth $\&$ development ) study protocol: factors that impact linear growth in children 9 to 15 years of age in Matiari, Pakistan. https://doi.org/10.1136/bmjopen-2018028343

Dormus, K. 2019. The development of coeducation in Poland against European backdrop ( 19th-21st century ), 01027, 110 .

Horak, P., Valge, M., Fischer, K., Magi, R., \& Kaart, T. 2018. Parents_of_early- 
maturing_girl.pdf.

Evolutionary

Applications, 12(1 Feb 2019), 10501061.

Hurwitz, L. B., Lovato, S. B., Lauricella, A. R., Woodruff, T. K., Patrick, E., \& Wartella, E. 2018. "A New You, That's Who": an evaluation of short videos on puberty and human reproduction. Palgrave Communications. https://doi.org/10.1057/s41599-018$0147-\mathrm{z}$

Nurfadhilah. 2019. Analisis Pendidikan Karakter Dalam Mempersiapkan Pubertas Menuju Generasi Emas Indonesia 2045. JPD: Jurnal Pendidikan Dasar, 10(31-052019), 85-100. https://doi.org/10.21009/JPD.010.09

O’Keeffe, L., Frysz, M., Bell, J. A., Howe, L. D., \& Fraser, A. 2019. Puberty timing and adiposity change across childhood and adolescence: disentangling cause and consequence.

Sari, R. 2017. Peran Orang Tua dalam Mendidik Anak pada Masa Pubertas di Desa Pulo Kambing Kecamatan Kluet Utara Aceh Selatan.

Smith, T. E., Panisch, L. S., Malespin, T., \& Graça Pereira, M. 2017. Evaluating effectiveness of abstinence education. Journal of Evidence-Informed Social Work, 14(5), 360-367. https://doi.org/10.1080/23761407.2017.1 340860 .
Steiner, R. 1996. The Education of The Child. New York: Anthroposophic Press.

Suhardi, D., Budhiman, A., Utami, R. P., Fathoni, M. K., A, D. K., Suhadisiwi, I., ... Aditama,

M. A. 2018. Panduan Praktis Implementasi Penguatan Pendidikan Karakter (PPK) Berbasis Kelas. (R. P. dkk Utami, Ed.). Jakarta: Kemendikbud.

Tabong, P. T., Maya, E. T., Adda-balinia, T., Kusi-appouh, D., Birungi, H., Tabsoba, P., \& Adongo, P. B. 2018. Acceptability and stakeholders perspectives on feasibility of using trained psychologists and health workers to deliver school-based sexual and reproductive health services to adolescents in urban Accra, Ghana, 1-17.

Week, H. \& M. 2018. Endocrine System Diseases and Conditions - Precocious Puberty; Findings from Yonsei University Reveals New Findings on Precocious Puberty ( Evaluation of characteristics of the craniofacial complex and dental maturity in girls with central precocious pub. Health \& Medicine Week, 1-3. 